\title{
Assistive Technology for People with Dementia: An Overview and Bibliometric Study
}

\author{
Ikram Asghar*, Shuang Cang† \& Hongnian Yu* \\ *Faculty of Science and Technology, Bournemouth University (BU), Poole, Dorset, UK, and \\ †Faculty of Management, Bournemouth University (BU), Poole, Dorset, UK \\ Correspondence: Hongnian Yu, Faculty of Science and Technology, Bournemouth University (BU), Fern \\ Barrow, Talbot Campus, Poole, Dorset BH12 5BB, UK. E-mail: yuh@bournemouth.ac.uk
}

Abstract

Background: This study presents an overview of recent research activities in assistive technology (AT) for people with dementia. Bibliometric studies are used to explore breadth and depth of different research areas, yet this method has not yet been fully utilized in AT research for people with dementia.

Methods: The bibliometric method was used for collecting studies related to AT. Based on inclusion/exclusion criteria, the AT studies with a focus on people with dementia are considered.

Study Scope: The study is based on factors such as; number of publications, citations per paper, collaborative research output, P-Index, major research and application areas and national dementia strategies.

Data Collection: Data was collected from 2000-2014 in AT research. The top 10 countries are selected based on their research outputs.

Results: USA emerged as the leading contributor with 503 publications and an annual growth rate of $16 \%$, followed by UK with 399 publications and growth rate of 22\%. Germany with 101 publications is on the 6th place, but it has a higher citation rate $16.43 \%$ as compared to USA (13.34\%). Although all 10 countries show good collaborative research output, Italy, Spain and Netherlands emerge as top collaborative research contributors with high percentages (84\%, 84\% and 79\%). All the top 10 countries, except Canada, Germany and Spain have national dementia strategies in place.

Conclusion: The overall analysis shows that USA and UK are working extensively in AT research for people with dementia. Both these countries also have well established national dementia strategies. 
Key Messages

- A bibliometric study gives useful data for documenting and analysing different countries contribution for a specific field of interest.

- This overview gives insights into how developed countries are investing into research on AT for the wellbeing of people with dementia.

- Developed countries usually invest more in AT research that is why these countries lead the research field. More investment from developing countries is needed to increase research.

- Health information scientists should empirically investigate the national dementia strategies of different countries and its impact on the lives of the people with dementia.

- The national dementia strategies can act as an information roadmap for developing countries to be ready for the ageing challenge in the near future. 


\section{Introduction}

From the start of the 21st century, dementia has been recognized as a priority for health and social care, especially in industrialized and developed countries ${ }^{1}$. Dementia is a broad category of "brain diseases that includes any disease that causes loss of cognitive ability (the ability to think and reason clearly) that is severe enough to affect person's daily functioning",2. It is a complicated disease with over 100 types of symptoms. The recent figures show that there are over 44 million people with dementia which is more than the individual population of 211 countries worldwide. Furthermore economically it hinders the world economy with a total of over $\$ 604$ billion annually which is more than the annual GDP of 158 countries individually ${ }^{2}$. Various surveys show that dementia costs the UK economy over \$37 billion each year, which is far more than the combined costs of heart diseases and cancer. The average cost of dementia per person per annum is $\$ 38,819$ which is more than the average salary of a person in the $\mathrm{UK}^{3}$. This overview is carried out on using assistive technology (AT) for people with dementia ${ }^{4-7}$. According to Hersh and Johnson, AT is defined as “ $a$ generic term that covers technologies, equipment, devices, apparatus, services, systems, processes and environmental modifications used by disabled and/or elderly people to overcome the social, infrastructural and other barriers to independence, full participation in society and carrying out activities safely and

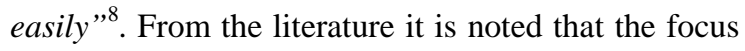
of AT research so far has been on the issues related to the wellbeing of people with dementia as well as proposing new technologies to improve this ${ }^{7,9}$. To the best of our knowledge there are no studies reported in the literature on analysing the statistic of AT research in different countries specifically in the context of people with dementia. This overview is initiated with the aim to investigate which countries are leading AT research for people with dementia and what are their major contributions. The overview addresses the following four research questions.

RQ1: Which are the leading research countries in AT research for people with dementia?

RQ2. What major fields exist within AT research for people with dementia?

RQ3: What is the collaborative research output for these major AT research countries?

RQ4: Which of the major AT research countries have a national dementia strategy?

\section{Methodology}

The research methodology used for this overview is adopted from Braun whose approach focuses on monitoring the trend of a new field of technology in the simplest way by analysing bibliometric quantification of that specific term in journals databases for a determined period ${ }^{10}$.

There are a number of studies published on bibliometric data analysis. Most work done on bibliometric data analysis can be found in nanoscience and nanotechnology $y^{11-14}$. To the best of our knowledge, a bibliometric study focusing on AT for people with dementia is not available in the current literature.

In this overview several aspects of the dementia AT research growth in leading countries are explored. These aspects include:

(1) Growth of publications and citations in the new millennium (2000-2014).

(2) Quality of publications defined by two important parameters, average citation per paper and the P-Index. 
(3) Internationally collaborated publications.

(4) Analysis of research outcome by top 10 leading AT research countries.

This overview is based on data obtained from Scopus [www.scopus.com], which is the largest abstract and citation database of peer-reviewed literature in the world $^{15}$. Scopus has 50\% more publishers and twice the number of titles than any other database. Scopus updated daily includes the most current research.

Figure 1 shows the search strategy used in this study which is adapted and modified from Jalali \& Wohlin $^{16}$. The scope of the overview is defined from aspects related to AT for people with dementia. Defining the scope helps in research question formulation and selecting appropriate keywords. The initial search keywords used include: assistive technology/technologies, assisted living, rehabilitation devices, Dementia and Alzheimer, for the period 2000 to 2014. Based on initial keywords, more keywords were found and the search string was developed. The search string used was: ((Dementia* OR Alzheimer* OR cognitive impairments* OR memory*) AND (Software* OR Web Application* OR Web App* OR Mobile Application* OR Medication tool* OR Diagnostic tool* OR Mobile App* OR Prompts* OR Reminder* OR Computer Program* OR Game* Android* OR Smart Phone* OR Tablet* OR iPad* OR Mobile Device* OR Media Player* Interface*)). After standardizing the data by removing irrelevant and duplicate papers, 1909 publications were considered relevant for bibliometric analysis.

\section{Results}

\section{Overall Research Scenario}

The overall scenario for AT related research publications for 2000 to 2014 is depicted in Figure 2. The number of publications in Scopus rose:
- $\quad$ By a factor of over 5 from 8 in 2000 to 42 in 2004.

- $\quad$ By a factor of 3 from 42 in 2004 to 135 in 2008.

- $\quad$ By a factor of 2 from 135 in 2008 to 323 in 2013 and then dropped to 248 in 2014.

The drop in 2014 may be due to some publications that are not added to/indexed in Scopus, as we conducted the search in February 2015.

As is clearly evident from the earliest results shown in Figure 2, AT research for people with dementia was at the exploratory stage at the start of the new millennium with barely a few publications till 2003. From 2004 to date there is a sharp and continuous increase in the number of publications for AT.

Overall there is $29 \%$ growth in the first 15 years of the $21^{\text {st }}$ century. This increase is the result of the realization of dementia's importance due to its economic impacts on bigger economies of the world ${ }^{1}$. Currently, due to the economic implications, various governments have started investing and companies are developing AT for the wellbeing of people with dementia.

\section{Research Scenario for Top 10 leading AT research Countries}

According to Thomson Reuters, the greater the number of papers are, the greater the chance of more citations and hence the impact ${ }^{17}$. Some studies highlight the number of papers as the measure of productivity as well ${ }^{18}$. Therefore the number of papers published in a country can be a good indicator of its research output against the investments made by the government.

Table 1 presents 'total number of publications' for the top 10 countries. While Figure 3 represents yearly increase in the number of AT publications along with average growth rate of each country. The country 
representation is assigned based on the location of the first author.

United States of America (USA) clearly takes the lead with a total of 503 publications and almost $26 \%$ of the combined publications by all other countries in these first 15 years of 21st century. USA has a steady average growth rate of $16 \%$ right throughout the specified period. Although UK, Canada and Sweden have almost similar average growth trend of $22 \%$ each, still UK stands at number two with overall 399 publications which is almost double in number to its nearest competitor Canada with 200 publications and Sweden with 140 publications.

Italy, Germany and Netherlands stand at number five, six and seven respectively with overall publication numbers 110, 101 and 100 but all these countries show good growth rates with 31\% (Italy), 28\% (Germany) and 24\% (Netherlands).

A close look at their average growth rates shows that these countries (Italy, Germany and Netherlands) have focused in this research area since 2007.

The remaining countries (France, Australia and Spain) have 87, 81 and 73 overall publications respectively with rather similar average annual growth rates of $20 \%, 20 \%$ and $18 \%$.

\section{Quality of Publications}

As is evident from the literature the number of citations gained by a research publication is one of the effective and easy to use measures of the importance of that publication ${ }^{19}$. Therefore, the average number of citations per paper (C) represents a fair picture of the quality (impact) of publications for each country.

Table 3 presents data for the publications shown in Table 1; in terms of the number of times those papers have been cited by other studies. Average citations per paper are shown in the second last column in Table 3 for the period 2000 to 2014.

In the research literature, quality of publications is determined by using different parameters in the previous research studies. The quality parameters include $\mathrm{H}$-Index ${ }^{20}$, G-Index ${ }^{21}$, HG-Inde ${ }^{22}$ and PInde ${ }^{23}$. Each of them has some advantages and limitations. These indexes are compared in Table 2.

Recent studies related to comparative analysis prefer to use the P-Index which provides a fair balance between the quantity (as determined by citations $\mathrm{C}$ ) and quality (as determined by the ratio $\mathrm{C} / \mathrm{P}$ ), where $\mathrm{P}$ is the total number of publications ${ }^{10,19}$.

The performance index is defined as:

$$
\mathrm{p}=[\mathrm{C} .(\mathrm{C} / \mathrm{P})]^{1 / 3}
$$

The last column in Table 3 shows P-Index for each country calculated using the above formula. From Table 3 these 10 countries can be divided into two groups. The $1^{\text {st }}$ group with a better P-Index $(\mathrm{P}>22.00)$ and $C$ value $(C>9.00)$, whereas the $2^{\text {nd }}$ group with an acceptable P-Index $(\mathrm{P}>10.00$ and <21.99) and C value $(\mathrm{C}>2.00$ and $<8.99)$.

According to the above mentioned criteria the $1^{\text {st }}$ group includes USA, UK, Canada, Germany and Australia. Table 3 shows USA has the highest number of publications and the highest P-Index of 44.73 and a good $C$ value of 13.34. However performance of Germany is notable. Although it has produced 4 times less research papers as compared to USA, it has the best $\mathrm{C}$ value of 16.43 and a high PIndex 30.09. These statistics indicate that the most papers from Germany are better quality and published in the high impact factor journals (impact factor $>1.0$ ). Among other countries UK (P-Index: 33.57 and C: 9.74), Canada (P-Index: 30.74 and C: 12.05) and Australia (P-Index: 24.27 and C: 13.28) have performed well in producing better quality 
research and being published in the high impact factor journals.

The $2^{\text {nd }}$ group includes Sweden (P-Index: 21.11 and C: 8.20), Italy (P-Index: 14.11 and C: 5.05), Netherlands (P-Index: 18.50 and C: 7.96), France (PIndex: 16.57 and C: 7.23) and Spain (P-Index: 10.98 and C: 4.26). These countries have the acceptable value for $\mathrm{C}$ and $\mathrm{P}$-Index, which indicate that the most papers by these countries have been published in the medium impact factor journals (impact factor $>.50$ and $<1.0$ ).

\section{Collaborative Research Output}

The collaborative research output includes those publications which have international co-authors. For the purpose of this review collaborative research includes the following types of research publications:

- Doctoral or Post-Doctoral research carried out in a foreign country.

- Foreign faculty members hired by universities and used address of their parent university.

- Foreign researchers hired by research organizations and used address of their parent organizations.

- Research studies with foreign universities under collaborative research projects.

- Research teams residing in different countries.

Figure 4 shows trends of the collaborative research output for the top 10 countries. Almost all countries have considerable collaborative research output. Italy, Spain and Netherlands emerged as top collaborative research countries with very high percentages $84 \%$, $84 \%$ and $79 \%$ respectively.

\section{AT Application Focus in Different Countries}

A closer analysis indicates that different countries have their own focus areas of AT research and its applications.
The focus of AT research in the USA is related to remote monitoring of people with dementia through activity recognition, which help them to remain at their homes for a longer period of time. The idea of digital cities for elderly people is another popular research area ${ }^{24-26}$.

Most of the research done in the UK is related to Tele-care. While using social care in combination with AT for the wellbeing of people with dementia is equally popular in the UK and Germany ${ }^{27-30}$. Additionally German researchers are also focused on providing assistance to people with dementia through activity monitoring ${ }^{31}$.

Simple and specialized mobile phone based AT for setting reminders and prompts for cognitive help to people with dementia are also gaining importance from researchers in the UK and the USA ${ }^{5,28,32-35}$.

AT research activities in Canada and France are mainly focused on use of robotics based technologies for providing help and social interaction to people with dementia ${ }^{4,36,37}$. Other interesting AT research areas in Canada includes the use of electronic organizer for cognitive help and sensors for health care $^{7,38}$.

Use of monitoring AT for decreasing fall risk is another focused area for researchers in France and the Netherlands $\mathrm{s}^{36,39-41}$.

Human like assistive communication robots for the emotional wellbeing of people with dementia are used in Australia $^{42,43}$. AT supported leisure activities are also hot research area for research in Australia for wellbeing of people with dementia ${ }^{44}$.

Mobility devices for safe walking and wellbeing management of people with dementia are top research interests in Spain for AT research ${ }^{45,46}$.

AT research in Sweden usually revolves around improving interaction among people with dementia 
and their care givers through specialized devices like tailored mobile phones and video mock-ups ${ }^{6,47}$. For improving rehabilitation of people with dementia, timing devices are also commonly used for safety of older adults living at their homes ${ }^{48}$.

Most of the AT research activities in Italy are focused on ambient intelligence for cognitively impaired people with dementia ${ }^{49}$.

\section{National Dementia Plans of the Top 10 Countries}

There are a few studies already published on national dementia strategies for some individual countries. Authors such as Marc Wortmann suggest that the national dementia strategies for different countries can better managed by following the procedures adapted for preparing diabetes and HIV/AIDS strategies for those countries. This study further emphasizes the need of comparing dementia strategies of different countries ${ }^{50}$. Another study highlights features of Japanese national dementia policy with international standards. The results show that Japan has multiple access points for dementia care for the elderly people. However fragmentation remains to be solved in dementia health care pathways $^{51}$. In another study a person centric approach is followed for studying dementia strategies for some countries. The current dementia strategies mostly help in early transition of the dementia journey, while the future strategies should focus on later transitions as well ${ }^{52}$.

The literature investigation further highlights, that there are no comparative studies available on national dementia strategies of different countries ${ }^{50,51}$. This overview examined the existence of national dementia strategies in the top AT countries. Seven of these 10 countries have their own national dementia strategies in place. Usually these plans are made with the collaboration of Alzheimer's Disease International (ADI) which helps to deal with the impacts of dementia on each country. These individual plans developed through ADI are able to resolve issues through a system customized to distinct culture and demographics of that specific country ${ }^{53}$. Typically a government national plan for dementia includes objectives such as:

- To promote awareness among common people about dementia and combating stigma.

- To identify AT support for dementia at every stage of this disease.

- To measure the population effected with dementia.

- To improve health-care quality through AT, social care and long term support.

- To ease access to diagnosis and AT services.

Table 4 summarises different statistics related to dementia population, investments and national strategies for all 10 countries.

USA - Currently there are 5.3 million people with dementia in the USA which is estimated to rise to 13.8 million by 2050 . It costs USA economy $\$ 226$ billion each year that can rise to $\$ 1.1$ trillion by 2050 . The USA released a national plan for fighting Alzheimer's and dementia in May 2012. This plan is based on the National Alzheimer's Project Act in 2011. This plan demands broad collaboration between states, private firms and non-profit organizations. The plan was updated in October $2015^{54}$. The major goals of the USA national plan include:

- Effectively prevent and treat Alzheimer's disease by 2025 .

- Enhance care quality and efficiency

- Expand supports for people with Alzheimer's disease and their families. 
- $\quad$ Enhance public awareness and engagement

- Improve data to track progress.

UK - According to recent figures 850,000 people across the UK have dementia; this number is expected to rise to one million by 2025 . The economic costs for dementia in the UK are estimated at $\$ 37$ billion per annum. To tackle this issue the department of health issued "Living well with dementia: A National Dementia Strategy” in 2009. The major aim of this strategy revolved around making major improvements in three core areas: to improve awareness, to diagnose early and intervention and to provide a higher quality care. Furthermore this strategy identified 17 core objectives which can be implemented at the local level.

The UK is one step ahead from other countries in realizing dementia's importance and its prime minister launched a program called "Prime Minister's challenge on dementia” in March $2012^{55}$. The major milestones of the program are:

- By 2015, two-thirds of people should have a diagnosis, with appropriate post diagnosis support.

- Creating dementia-friendly communities that understand how to help.

- Over 100,000 members of the public through dementia awareness sessions.

- \$70.4 million funding in dementia projects mostly related to social science and technology.

- By 2025, a new generation of research leaders able to continue to expand the UK's capability for applied dementia care underpinned by excellent research.

Canada - Canada is yet to have a national strategy for dementia, although "Rising Tide" a nongovernmental group is persuading the Canadian government to have a national strategy for dementia as dementia figures in Canada are rising in recent years ${ }^{56}$. According to a recent study the number of people with dementia living in Canada is over 747,000 and the number will be double by 2031 . Dementia is impacting Canadian economy \$33 billion each year and by 2040 it will rise to $\$ 293$ billion per annum ${ }^{56}$.

The Alzheimer Society is trying to convince the government to come up with a national strategy for dementia focused on the following points:

- Increasing amount of funding for dementia research in all aspects.

- Promoting earlier intervention through early diagnosis.

- Dementia workforce skills enhancement through training.

- Recognizing and improving support for caregivers.

Sweden - Currently 173,135 people have dementia in Sweden. In 2010, the first Swedish national policy for dementia was proposed with the purpose of supporting decision makers for social services and healthcare. As this policy encourages people to go for annual check-ups, an increase of 7,000 people per year is expected which will cost $\$ 5$ to 7 million. This increase in regular examination will result into less cost for dementia related disease every year. The Swedish national strategy for dementia revolves around diagnosis, treatment and research. Although most research in Sweden is carried out in universities, but there is also an institute for brain research (Swedish Brain Power) working actively in this area $^{57}$.

Italy - According to 2014 estimates there are 1,272,317 people with dementia in Italy. Italy's dementia strategy was developed by close 
cooperation of health ministry, three national patient/career associations and National Institute of Health (NIH). The newly proposed dementia strategy is being implemented at regional and national levels ${ }^{58}$. The dementia strategy is based on four major objectives:

- Promoting policies and actions for social approach and public health.

- Developing the network of integrated services

- Implementing policies for high quality care

- Improving people with dementia quality of life along their families through eliminating stigma.

Germany - In Germany 1,572,104 people have dementia and this number is expected to rise up to 2.5 million by 2030. Although dementia costs German economy $\$ 2.6$ billion every year, there is no national strategy for dementia in place currently. Dementia related issues are generally addressed by various ministries including (health, research, family and social affairs). Recently the German Alzheimer Association is pressurizing the government to have a national strategy for dementia. Now, German government in association with "Allianz für Menschen mitDemenz" has launched an agenda for dementia with the title "Together for People with Dementia”. By 2017 the government plans to have more care-homes for people with dementia by increasing local support networks ${ }^{59}$.

Netherlands - There are 245,560 people with dementia in Netherlands. Netherlands developed its strategy for dementia care from January 2011 to May 2012. This strategy is based on care, welfare, housing and treatment of people with dementia according to their wishes. Since 2012, the strategy is being used for purchasing integrated care in 85 care networks for dementia. This dementia program will last for eight years. The Netherlands national strategy is quite similar to the Swedish national strategy as it also revolves around factors of diagnosis, treatment and research $^{60}$.

France - In France there are 1,174,956 people with dementia. France had two dementia plans in 2000 and 2004 but there were no specific budgets allocated for research in those plans ${ }^{61}$. In February 2008, France launched its $3^{\text {rd }}$ plan for dementia when their president chose to fight against dementia as a critical challenge $^{62}$. This plan was based on three major dimensions:

- Improving patient and their care-giver quality of life.

- Having proper knowledge for action

- Organizing for a social concern

The government also allocated about $\$ 1.8$ billion funding for carrying out these plans over the next five years. A national steering committee was formed to look into the progress and implementation of the national plan.

Australia - Currently there are 342,800 people living with dementia in Australia. In next 10 years this number is expected to increase to 400,000 . In 20092010 the total cost spent for diseases related to dementia was $\$ 4.9$ billion which is expected to increase to $\$ 83$ billion by 2060 . Taking these figures into account, Australia has their national strategy for dementia with the title "Fight Alzheimer, Save Australia” in place since 2006. This national strategy is based on four key areas of focus:

- Improving support and empower consumers

- Ensuring better quality of dementia care

- Increasing understanding and awareness of dementia.

- Identifying useful strategies to prevent and delay inception of dementia. 
For implementing these key areas, Australians are developing dementia friendly communities similar to the UK and also celebrating dementia awareness weeks every year ${ }^{63}$.

Spain - In Spain there are 818,347 people with dementia. Spain does not have a national strategy for dementia at government level so far. However, the Spanish Alzheimer Federation (CEAFA) and the "Alzheimer's Alliance" aim to convince the government for a national dementia plan. Currently most dementia patients have to pay $40 \%$ of the costs of the pharmaceutical products used for their treatments, while on some items the discount is up to $90 \%$. Some categories of people like pensioners don't have to pay anything for their treatments ${ }^{64}$.

\section{Discussion}

To the best of our knowledge, this is the first study to investigate the AT research contribution of different countries for people with dementia. In recent years AT research is transforming from the exploratory stage to the implementation stage. This boom is largely because of the recent focus of academic researchers and industrial experts on design and development of AT for the wellbeing of people with dementia. The results show that from 2004, the AT research witnessed steady increase in publications with USA and UK contributing almost $50 \%$ of the total research. Other indicators like average research growth, citations per paper and the P-Index also acknowledges USA and UK's leading the numbers.

The high P-Index values indicate that along USA and UK, the research studies from Canada and Germany are of good quality and published in the high impact journals.

Italy and Netherlands lead the way for collaborative research as most of their studies are done in collaborative projects with one or more countries.
Further analysis shows, that all these countries have their own specialities in research related to AT. The major AT research interest and application include tele-care, activity monitoring, fall detection, socialization, specialized mobile phones for communication, robotic based assistance, sensors, mobility devices, prompts and reminders etc. The health information scientists can conduct further studies to explore the research interests of each country as they have basic knowledge and required skills for such research. The country based research interests can help in finding similar research interests and collaborative projects.

Strong national dementia strategies also play an important role in research for the wellbeing of people with dementia. The countries like UK, USA and France have well established dementia strategies at national level. These strategies guide them for better AT research because of the already established research goals, objectives and priorities. The countries not having national dementia strategies including Canada, Germany and Spain are all working towards their national dementia strategies.

The findings from the overview have insights for researchers and industry on the level of AT research in different developed countries, the major research areas, research applications and national dementia strategies for the top AT research countries. The health information scientists utilizing their knowledge and expertise should investigate national dementia strategies for individual countries and compare these strategies with already wellestablished national dementia strategies of USA and UK. Dementia is going to affect developing countries as well in near future. Such empirical studies will help the developing countries with fewer resources to take advantage from developed countries experiences 
to develop their own national strategies for dementia. The similar studies using the same methodology can be performed in other research areas like; AT research for people with disabilities, AT usage for special children in education, AT impact studies with regard to society etc.

After close analysis of data, the following research directions are proposed for future research.

\section{Eastern View for AT Research for Dementia}

From 2000 to 2014 there are a total of 1909 publications for AT research for dementia. 1793 (94\%) of the total number of publications are from the top 10 countries. Other than Australia all countries are from the West. So, it can be assumed that current research is a western view of AT research for dementia. More efforts are needed from eastern countries of the Asia Pacific for research the on topic under investigation (AT for dementia). Currently the Asia Pacific holds almost 4 billion people and the dementia population of this region will rise to 71 million till 2050 ${ }^{(65)}$. Countries especially China, Japan, South Korea, India, Indonesia, Malaysia, Pakistan, and Thailand need to invest more in their aging and dementia research programs as $70 \%$ of the dementia investments come from Western countries and there is only a small portion from eastern countries $^{65}$. Furthermore Asian countries should also come up with national strategies to tackle challenges of dementia as already done by Japan, South Korea and Indonesia ${ }^{65}$.

\section{Involving Social Care in Combination with AT}

Although there is research going on AT development for people with dementia and helping people with dementia to have quality life, still literature suggests that too much use of AT brings aggression in people with dementia as they believe that by adopting AT, their family and care-givers will reduce their visits to them ${ }^{6}, 35$. Therefore, there is a strong need for cooperation between academia and industry to manage this challenge by adopting a balance between AT and human care factor for better results.

\section{Software Based AT for People with Dementia}

Close analysis of literature indicates that most available AT for people with dementia lies in the category of robotics based AT, health and patient monitoring based AT, reminders based AT and communication based $\mathrm{AT}^{66}$. The literature suggests that currently there are only a few software related AT for people with dementia which demand more efforts from software engineers to design and develop more AT for helping people with dementia ${ }^{37,38}$. Therefore, software applications development for assisting people with dementia is another area of great potential.

\section{Research Output of UK and USA Universities}

The results indicate that USA and UK play an important role in dementia research and have well established national dementia strategies in place. As most of the research comes from the universities, another interesting future research direction can be analysing the research outputs for USA and UK at university level. This will provide insights into institutional contribution, their research interests, areas of expertise and impact for dementia research. The results of such studies can open new ways for collaborative research between different institutions with different expertise.

\section{Study Limitations}

This overview has the following potential limitations: 
1) The reviewed papers were searched from the Scopus database only; in the future the other database should be considered.

2) This study only includes the papers published from 2000 to 2014.

3) Additionally the papers used in this study are in English language only, which may bias the results towards English speaking countries.”

\section{Conclusions}

The early part of the 21st century has seen dementia as one of the leading challenges. Various techniques including AT are now developed and adopted to help people with dementia to live independently. Taking these developments into account this overview analysed AT research for people with dementia for 2000-2014 around the world. Data was taken from the Scopus. Research parameters such as the number of studies, citations, P-Index, collaborative research output, major research areas were considered for this study. Based on these parameters the USA, UK, Canada, Sweden, Italy, Germany, Netherlands, France, Australia and Spain emerged as the top 10 AT research countries for dementia.

The national dementia strategies for these countries are discussed individually. Other than Canada, Germany and Spain the remaining seven countries have dementia strategies in place at the national level. France was one of the first countries to have a national dementia strategy, while Italy is the latest country to have it. In countries that don't have national dementia strategies, there are continuous protests from NGO's and other health organizations to persuade their governments to form national dementia strategies.

Through analysis of all these parameters, we can see that USA and UK are more focused on this area of research. Furthermore, these two countries have strong and well established national dementia strategies in place. On the other hand, Canada and Germany performed high on the P-Index as most of their research is published in high impact journals.

The health information scientists can produce country based research interests and hence help in improved opportunities for research collaboration. They can also assist developing countries in shaping their national dementia strategies.

Current work reflects the Western view of AT research for dementia. There is need for academia and industry from other countries to invest more efforts in this field. Another important direction for future research is the involvement of social aspects in AT research for gaining better results through the balance of technology and social care. Software based AT for dementia is another potential field for researchers to explore upon.

\section{Acknowledgements and Conflict of Interest}

The authors acknowledge the role of Bournemouth University and cLink (Erasmus Mundus) for funding this study. The authors further declare no conflict of interest for this study.

\section{References:}

1. Prince M, Bryce R, Albanese E, Wimo A, Ribeiro W, Ferri CP. The global prevalence of dementia: a systematic review and metaanalysis. Alzheimer's \& Dementia. 2013;9(1):63-75. e2.

2. Span M, Hettinga M, Vernooij-Dassen M, Eefsting J, Smits C. Involving people with dementia in the development of supportive IT applications: A systematic review. Ageing research reviews. 2013;12(2):535-51.

3. Sinclair D, Corazziari E, Martin P. INTERNATIONAL LONGEVITY CENTRE-UK, A 
think-tank impacting policy on longevity, ageing and population change. Analysis. 2013.

4. Wu Y-H, Wrobel J, Cristancho-Lacroix V, Kamali L, Chetouani M, Duhaut D, et al. Designing an assistive robot for older adults: The ROBADOM project. IRBM. 2013;34(2):119-23.

5. Donnelly M, Nugent C, McClean S, Scotney B, Mason S, Passmore P, et al. A mobile multimedia technology to aid those with Alzheimer's disease. IEEE multimedia. 2010;2(17):42-51.

6. Boman I-L, Lundberg S, Starkhammar S, Nygård L. Exploring the usability of a videophone mock-up for persons with dementia and their significant others. BMC geriatrics. 2014;14(1):49.

7. Imbeault $\mathrm{H}$, Bier N, Pigot H, Gagnon L, Marcotte N, Fulop T, et al. Electronic organiser and Alzheimer's disease: Fact or fiction? Neuropsychological rehabilitation. 2014;24(1):71100.

8. Hersh MA, Johnson MA. On modelling assistive technology systems-Part I: Modelling framework. Technology and Disability. 2008;20(3):193-215.

9. Hoey J, Poupart P, von Bertoldi A, Craig T, Boutilier C, Mihailidis A. Automated handwashing assistance for persons with dementia using video and a partially observable markov decision process. Computer Vision and Image Understanding. 2010;114(5):503-19.

10. Braun $\mathrm{T}$, Schubert A, Zsindely S. Nanoscience and nanotecnology on the balance. Scientometrics. 1997;38(2):321-5.

11. Karpagam R, Gopalakrishnan S, Natarajan M, Babu BR. Mapping of nanoscience and nanotechnology research in India: a scientometric analysis, 1990-2009. Scientometrics. 2011;89(2):501-22.
12. Tang L, Shapira P. Regional development and interregional collaboration in the growth of nanotechnology research in China. Scientometrics. 2011;86(2):299-315.

13. Gupta VK. Indian publications output in nanotechnology during 1990-2008. Advanced Science Letters. 2009;2(3):402-4.

14. Roco MC. The long view of nanotechnology development: the National Nanotechnology Initiative at 10 years. Journal of Nanoparticle Research. 2011;13(2):427-45.

15. Rew D. SCOPUS: Another step towards seamless integration of the world's medical literature. European Journal of Surgical Oncology (EJSO). 2010;36(1):2-3.

16. Jalali S, Wohlin C, editors. Agile practices in global software engineering-A systematic map. Global Software Engineering (ICGSE), 2010 5th IEEE International Conference on; 2010: IEEE.

17. Reuters T. Using bibliometrics: a guide to evaluating research performance with citation data. Philadelphia, Thomson Reuters. 2008.

18. Sahel J-A. Quality versus quantity: assessing individual research performance. Science translational medicine. 2011;3(84):84cm13-84cm13.

19. Bajwa R, Yaldram K, Hussain S, Ahmed T. Nanotechnology research among some leading OIC member states. Journal of Nanoparticle Research. 2012;14(9):1-10.

20. Hirsch JE. An index to quantify an individual's scientific research output. Proceedings of the National academy of Sciences of the United States of America. 2005:16569-72.

21. Egghe L. Theory and practise of the g-index. Scientometrics. 2006;69(1):131-52.

22. Alonso S, Cabrerizo FJ, Herrera-Viedma E, Herrera F. hg-index: A new index to characterize the 
scientific output of researchers based on the h-and gindices. Scientometrics. 2010;82(2):391-400.

23. Prathap G. The 100 most prolific economists using the p-index. Scientometrics. 2010;84(1):167-72.

24. Doukas C, Metsis V, Becker E, Le Z, Makedon F, Maglogiannis I. Digital cities of the future: Extending@ home assistive technologies for the elderly and the disabled. Telematics and Informatics. 2011;28(3):176-90.

25. Rowe MA, Kelly A, Horne C, Lane S, Campbell J, Lehman B, et al. Reducing dangerous nighttime events in persons with dementia by using a nighttime monitoring system. Alzheimer's \& dementia. 2009;5(5):419-26.

26. Carrillo MC, Dishman E, Plowman T. Everyday technologies for Alzheimer's disease care: Research findings, directions, and challenges. Alzheimer's \& Dementia. 2009;5(6):479-88.

27. Saborowski M, Kollak I. "How do you care for technology?”-Care professionals' experiences with assistive technology in care of the elderly. Technological Forecasting and Social Change. 2015;93:133-40.

28. Torrington J. The design of technology and environments to support enjoyable activity for people with dementia. ALTER-European Journal of Disability Research/Revue Européenne de Recherche sur le Handicap. 2009;3(2):123-37.

29. Leroi I, Woolham J, Gathercole R, Howard R, Dunk B, Fox C, et al. Does telecare prolong community living in dementia? A study protocol for a pragmatic, randomised controlled trial. Trials. 2013;14(1):349.

30. McCabe L, Innes A. Supporting safe walking for people with dementia: User participation in the development of new technology. Gerontechnology. 2013;12(1):4-15.
31. Peters C, Hermann T, Wachsmuth S, Hoey J. Automatic Task Assistance for People with Cognitive Disabilities in Brushing Teeth-A User Study with the TEBRA System. ACM Transactions on Accessible Computing (TACCESS). 2014;5(4):10.

32. Zhang S, McClean SI, Nugent CD, Donnelly MP, Galway L, Scotney BW, et al. A predictive model for assistive technology adoption for people with dementia. Biomedical and Health Informatics, IEEE Journal of. 2014;18(1):375-83.

33. Lauriks S, Reinersmann A, Van der Roest HG, Meiland F, Davies RJ, Moelaert F, et al. Review of ICT-based services for identified unmet needs in people with dementia. Ageing research reviews. 2007;6(3):223-46.

34. Wherton JP, Monk AF. Technological opportunities for supporting people with dementia who are living at home. International Journal of Human-Computer Studies. 2008;66(8):571-86.

35. Seelye AM, Schmitter-Edgecombe M, Das B, Cook DJ. Application of cognitive rehabilitation theory to the development of smart prompting technologies. Biomedical Engineering, IEEE Reviews in. 2012;5:29-44.

36. Aloulou H, Mokhtari M, Tiberghien $\mathrm{T}$, Biswas J, Phua C, Lin JHK, et al. Deployment of assistive living technology in a nursing home environment: methods and lessons learned. BMC medical informatics and decision making. 2013;13(1):42.

37. Mordoch E, Osterreicher A, Guse L, Roger $\mathrm{K}$, Thompson G. Use of social commitment robots in the care of elderly people with dementia: A literature review. Maturitas. 2013;74(1):14-20.

38. Hoey J, Boutilier C, Poupart P, Olivier P, Monk A, Mihailidis A. People, sensors, decisions: Customizable and adaptive technologies for 
assistance in healthcare. ACM Transactions on Interactive Intelligent Systems (TiiS). 2012;2(4):20.

39. Tchalla AE, Lachal F, Cardinaud N, Saulnier I, Bhalla D, Roquejoffre A, et al. Efficacy of simple home-based technologies combined with a monitoring assistive center in decreasing falls in a frail elderly population (results of the Esoppe study). Archives of gerontology and geriatrics. 2012;55(3):683-9.

40. Schikhof Y, Mulder I, Choenni S. Who will watch (over) me? Humane monitoring in dementia care. International Journal of Human-Computer Studies. 2010;68(6):410-22.

41. Tchalla AE, Lachal F, Cardinaud N, Saulnier I, Rialle V, Preux P-M, et al. Preventing and managing indoor falls with home-based technologies in mild and moderate Alzheimer's disease patients: pilot study in a community dwelling. Dementia and geriatric cognitive disorders. 2013;36(3-4):251-61.

42. Khosla R, Chu M-T, Kachouie R, Yamada K, Yamaguchi T, editors. Embodying care in Matilda: an affective communication robot for the elderly in Australia. Proceedings of the 2nd ACM SIGHIT International Health Informatics Symposium; 2012: ACM.

43. Khosla R, Chu M-T. Embodying care in Matilda: an affective communication robot for emotional wellbeing of older people in Australian residential care facilities. ACM Transactions on Management Information Systems (TMIS). 2013;4(4):18.

44. Nansen B, Vetere F, Robertson T, Downs J, Brereton M, Durick J. Reciprocal habituation: a study of older people and the Kinect. ACM Transactions on Computer-Human Interaction (TOCHI). 2014;21(3):18.
45. Martins MM, Santos CP, Frizera-Neto A, Ceres R. Assistive mobility devices focusing on Smart Walkers: Classification and review. Robotics and Autonomous Systems. 2012;60(4):548-62.

46. Kamel Boulos MN, Lou RC, Anastasiou A, Nugent CD, Alexandersson J, Zimmermann G, et al. Connectivity for healthcare and well-being management: examples from six European projects. International journal of environmental research and public health. 2009;6(7):1947-71.

47. Rosenberg L, Nygård L. Persons with dementia become users of assistive technology: a study of the process. Dementia. 2011:1471301211421257.

48. Nygård L. The stove timer as a device for older adults with cognitive impairment or dementia: Different professionals' reasoning and actions. Technology and Disability. 2009;21(3):53-66.

49. Bravo J, Coronato A, Curran K, De Pietro G, Ren Q, Sarrafzadeh M. Editorial to the special section on ambient intelligence and assistive technologies for cognitive impaired people. IEEE J Biomedical and Health Informatics. 2014;18(1):352.

50. Wortmann M. Importance of national plans for Alzheimer's disease and dementia. Alzheimer's research \& therapy. 2013;5(5):1.

51. Nakanishi M, Nakashima T. Features of the Japanese national dementia strategy in comparison with international dementia policies: How should a national dementia policy interact with the public health-and social-care systems? Alzheimer's \& Dementia. 2014;10(4):468-76. e3.

52. Fortinsky RH, Downs M. Optimizing person-centered transitions in the dementia journey: A comparison of national dementia strategies. Health Affairs. 2014;33(4):566-73. 
53. International AsD. Alzheimer's and dementia plans. 2015 [18-November-2015]; Available from: https://www.alz.co.uk/alzheimerplans.

54. Health UDo, Services H, Health UDo, Services H. National plan to address Alzheimer's disease. 2012.

55. Health Do. Prime Minister's challenge on dementia: delivering major improvements in dementia care and research by 2015. Department of Health London; 2012.

56. Dudgeon S. Rising Tide: The Impact of Dementia on Canadian Society: a Study: Alzheimer Society of Canada; 2010.

57. Westerlund K. National Dementia Strategies (diagnosis, treatment and research). 2014.

58. Fiandra TD. The New Italian National Strategy. 2014.

59. Europe A. The prevalence of dementia in Europe/Germany. 2014.

60. Europe A. The prevalence of dementia in Europe/Netherlands. 2014.
61. Europe A. National Dementia Strategies/France. 2013.

62. Le Duff F, Develay AE, Quetel J, Lafay P, Schück S, Pradier C, et al. The 2008-2012 French Alzheimer plan: description of the national Alzheimer information system. Journal of Alzheimer's Disease. 2012;29(4):891-902.

63. Australia As. Dementia statistics in Australia. 2015.

64. Europe A. Background information about the National Dementia Strategy/Spain. 2013.

65. International AsD. Dementia in the Asia Pacific Region. 2014.

66. Asghar I, Cang S, Yu H, editors. A systematic mapping study on assitive technologies for people with dementia. 2015 9th International Conference on Software, Knowledge, Information Management and Applications (SKIMA); 2015: IEEE. 
Assistive Technology for People with Dementia

\section{Figures}

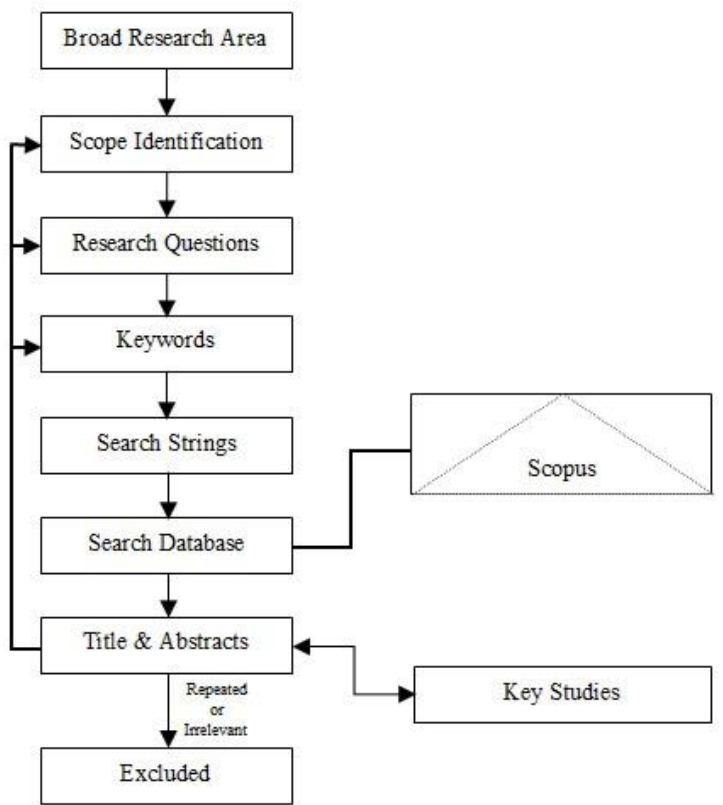

Figure 1: Search Strategy Used for the Study

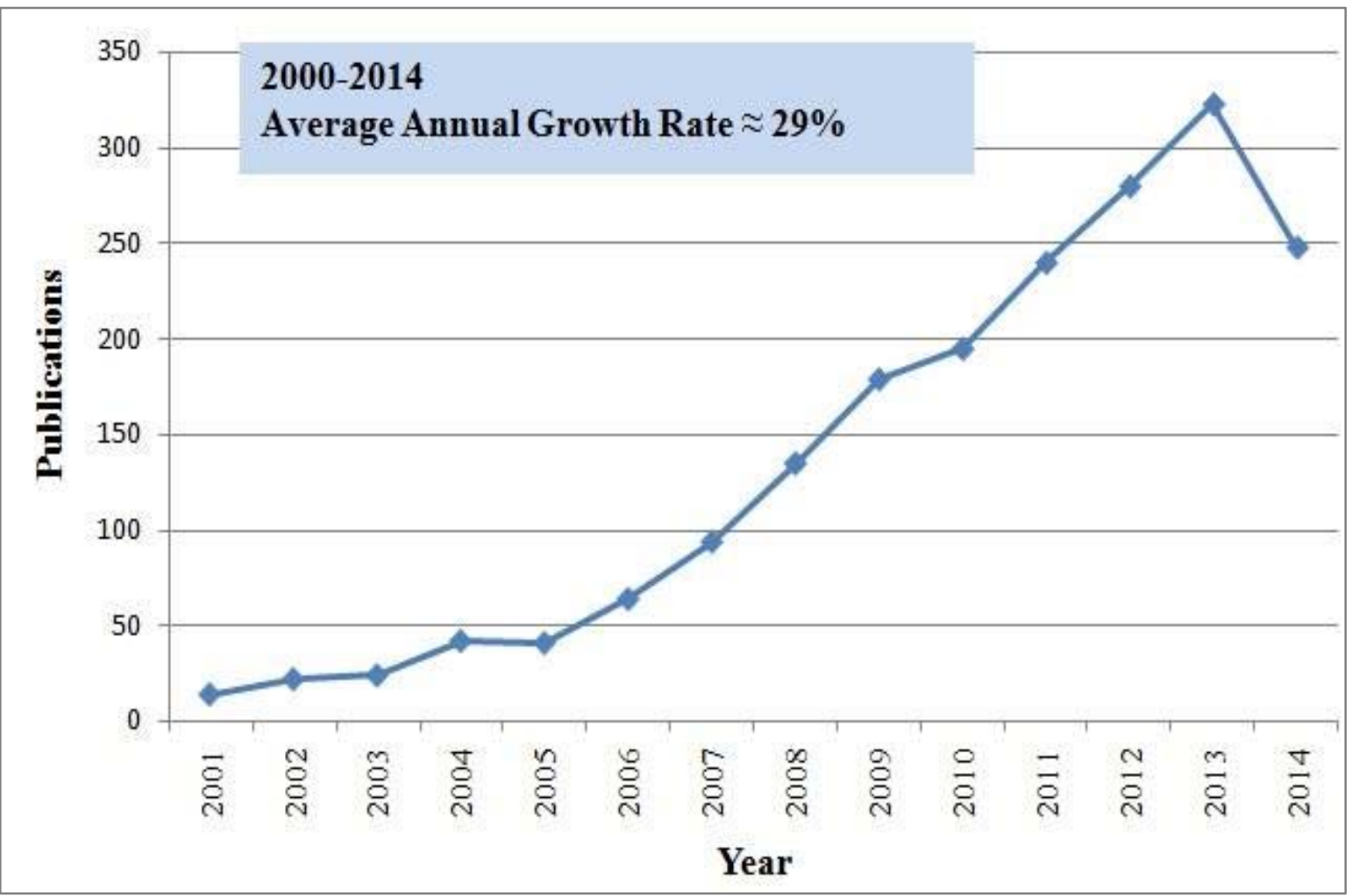

Figure 2: World-wide Growth for Publications in AT Research for Dementia (2000-2014) 


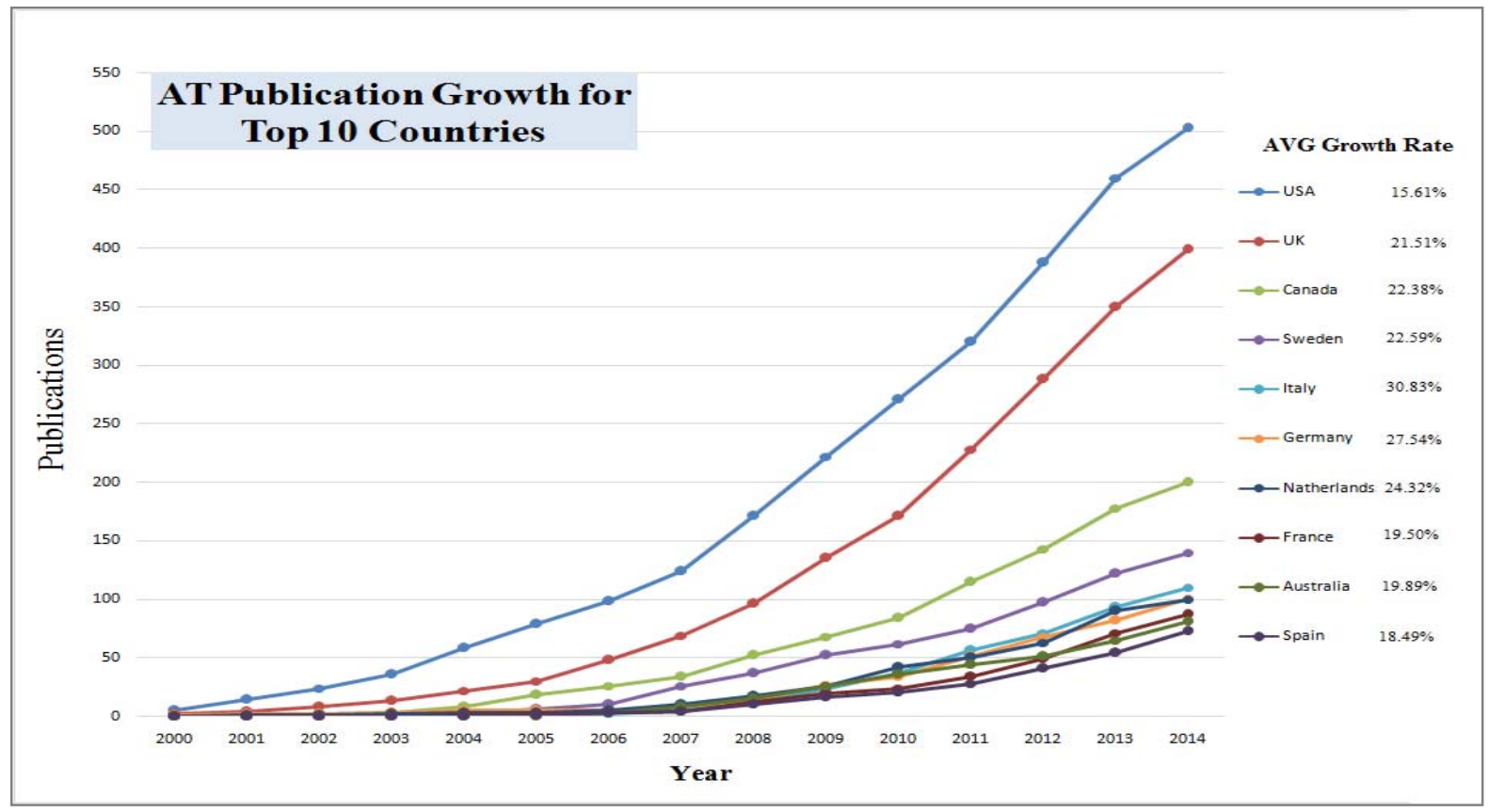

Figure 3: Growth in Publications in AT Research for Dementia (2000-2014) for Top 10 Countries

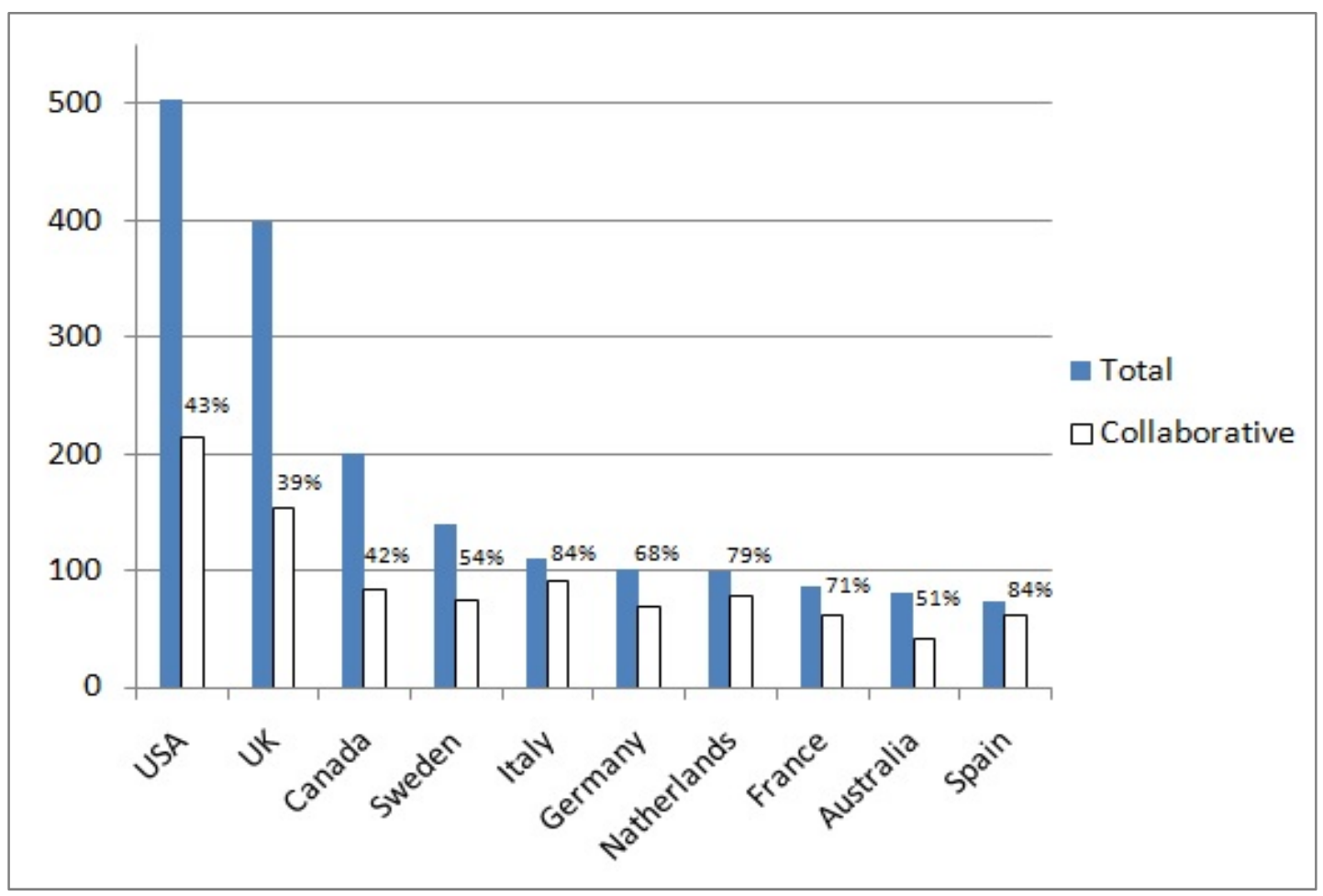

Figure 4: Collaborative Publications in AT Research for Dementia for the Period 2000-2014 for Top 10 Countries 
Assistive Technology for People with Dementia

\section{Tables}

Table 1: No. of Publications in AT Research for Dementia for the Period 2000-2014 for Top 10 Countries

\begin{tabular}{|c|c|c|c|c|c|c|c|c|c|c|c|c|c|c|c|c|c|}
\hline 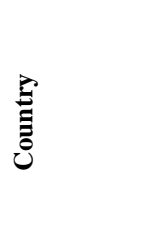 & ఫ્ి & 홍 & ชิ & ชి & ষ্ণ & 농 & ஜ̊ํํ & 응 & 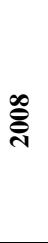 & 옹 & $\stackrel{\circ}{\stackrel{ }{2}}$ & $\overline{\overline{\text { N }}}$ & 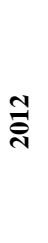 & $\stackrel{m}{\stackrel{\text { N }}{2}}$ & 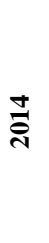 & 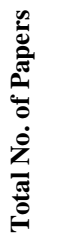 & 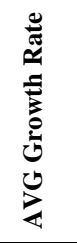 \\
\hline USA & 5 & 9 & 10 & 12 & 22 & 21 & 19 & 26 & 47 & 51 & 49 & 49 & 68 & 72 & 43 & 503 & 15.61 \\
\hline UK & 2 & 2 & 4 & 5 & 9 & 8 & 18 & 21 & 27 & 39 & 36 & 57 & 60 & 62 & 49 & 399 & 21.51 \\
\hline Canada & 0 & 1 & 1 & 1 & 5 & 10 & 8 & 8 & 18 & 16 & 16 & 31 & 28 & 35 & 22 & 200 & 22.38 \\
\hline Sweden & 0 & 0 & 0 & 1 & 2 & 3 & 4 & 16 & 11 & 15 & 10 & 13 & 22 & 25 & 18 & 140 & 22.59 \\
\hline Italy & 0 & 0 & 0 & 0 & 1 & 0 & 1 & 3 & 6 & 13 & 13 & 19 & 15 & 22 & 17 & 110 & 30.83 \\
\hline Germany & 1 & 1 & 0 & 1 & 2 & 0 & 0 & 3 & 6 & 13 & 7 & 17 & 17 & 14 & 19 & 101 & 27.54 \\
\hline Netherlands & 0 & 1 & 0 & 1 & 1 & 0 & 2 & 5 & 7 & 9 & 16 & 8 & 13 & 27 & 10 & 100 & 24.32 \\
\hline France & 0 & 0 & 0 & 0 & 1 & 1 & 1 & 1 & 8 & 7 & 5 & 10 & 15 & 22 & 16 & 87 & 19.50 \\
\hline Australia & 0 & 0 & 0 & 0 & 0 & 0 & 3 & 5 & 7 & 11 & 10 & 8 & 7 & 14 & 16 & 81 & 19.89 \\
\hline Spain & 0 & 0 & 0 & 0 & 0 & 1 & 2 & 1 & 6 & 6 & 4 & 8 & 13 & 13 & 19 & 73 & 18.49 \\
\hline
\end{tabular}

Table 2: Different Parameters for Quality of Publications

\begin{tabular}{|c|c|c|c|}
\hline Parameter & Definition & Advantages & Limitations \\
\hline H-Index & $\begin{array}{l}\text { Reflects both the number of publications } \\
\text { and the number of citations per } \\
\text { publication. }\end{array}$ & $\begin{array}{l}\text { - Measure the quality and quantity of } \\
\text { scientific output simultaneously. }\end{array}$ & $\begin{array}{l}\text { - Works only for same fields } \\
\text { comparisons. } \\
\text { - Can be manipulated through self- } \\
\text { citations. } \\
\text { - Just provide total number of } \\
\text { citations for a given scholar }\end{array}$ \\
\hline G-Index & $\begin{array}{l}\text { For a (set of articles) ranked in decreasing } \\
\text { order of the number of citations that they } \\
\text { received. }\end{array}$ & $\begin{array}{l}\text { - Show authors performance } \\
\text { - Helps to showcase authors' impact. } \\
\text { - Give value to low cited papers as } \\
\text { well. } \\
\text { - The high cited papers can bolster } \\
\text { the low cited papers. }\end{array}$ & $\begin{array}{l}\text { - Works on longer table of numbers } \\
\text { to reach your conclusions. }\end{array}$ \\
\hline HG-Index & $\begin{array}{l}\text { The HG-Index is computed as the } \\
\text { geometric mean of his h- and g- indices. }\end{array}$ & $\begin{array}{l}\text { - Provide more granularity then H } \\
\text { and G Indices. } \\
\text { - Easy to compare and understand. }\end{array}$ & $\begin{array}{l}\text { - Granularity does not necessarily } \\
\text { mean precision. } \\
\text { - Both H and G are defined on } \\
\text { ordinal scales. }\end{array}$ \\
\hline P-Index & $\begin{array}{l}\text { Provides a fair balance between the } \\
\text { quantity (as determined by citations C) } \\
\text { and quality (as determined by the ratio } \\
\mathrm{C} / \mathrm{P} \text { ), where } \mathrm{P} \text { is the total number of } \\
\text { publications. }\end{array}$ & $\begin{array}{l}\text { - Best balance for research quantity } \\
\text { and quality. } \\
\text { - The P-Index is more versatile as } \\
\text { compared with other indices. }\end{array}$ & $\begin{array}{l}\text { - It requires both citations and ratio } \\
\text { of citation data. }\end{array}$ \\
\hline
\end{tabular}


Assistive Technology for People with Dementia

Table 3: Citation Comparison for AT Research for Top 10 Countries of the World

\begin{tabular}{|c|c|c|c|c|c|c|c|c|c|c|c|c|c|c|c|c|}
\hline$\stackrel{\vec{E}}{\Xi}$ & ชิ ชิ & ชి & ষ্ণ & ํํㅇ & ஜ̊ํํ & ิㅗㅇ & 串 & 옹 & 을 & $\overline{\text { సิ }}$ & 곡 & $\stackrel{n}{\text { จิ }}$ & $\underset{\text { ন }}{\mathbb{N}}$ & 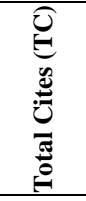 & 离 & 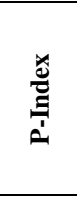 \\
\hline USA & 32 & 68 & 94 & 153 & 215 & 294 & 437 & 493 & 689 & 827 & 1002 & 1209 & 1172 & 6710 & 13.34 & 44.73 \\
\hline UK & 3 & 11 & 24 & 55 & 81 & 123 & 154 & 241 & 418 & 573 & 639 & 829 & 735 & 3886 & 9.74 & 33.57 \\
\hline Canada & 1 & 1 & 16 & 47 & 70 & 89 & 158 & 171 & 254 & 366 & 358 & 467 & 412 & 2410 & 12.05 & 30.74 \\
\hline Sweden & 0 & 0 & 1 & 6 & 17 & 40 & 65 & 114 & 106 & 140 & 179 & 253 & 227 & 1148 & 8.20 & 21.11 \\
\hline Italy & 0 & 0 & 0 & 0 & 3 & 7 & 11 & 24 & 32 & 55 & 80 & 147 & 197 & 556 & 5.05 & 14.11 \\
\hline Germany & 4 & 1 & 2 & 26 & 38 & 36 & 62 & 99 & 205 & 248 & 313 & 343 & 280 & 1659 & 16.43 & 30.09 \\
\hline Netherlands & 2 & 0 & 0 & 1 & 10 & 18 & 21 & 44 & 65 & 103 & 135 & 192 & 205 & 796 & 7.96 & 18.50 \\
\hline France & 0 & 0 & 0 & 0 & 2 & 1 & 8 & 35 & 73 & 79 & 121 & 147 & 163 & 629 & 7.23 & 16.57 \\
\hline Australia & 0 & 0 & 0 & 0 & 0 & 1 & 27 & 79 & 153 & 203 & 211 & 237 & 165 & 1076 & 13.28 & 24.27 \\
\hline Spain & 0 & 0 & 0 & 0 & 2 & 4 & 8 & 14 & 25 & 33 & 58 & 68 & 99 & 311 & 4.26 & 10.98 \\
\hline Total & 42 & 81 & 137 & 288 & 438 & 613 & 951 & 1314 & 2020 & 2627 & 3096 & 3892 & 3655 & 19181 & & \\
\hline
\end{tabular}

Table 4: Summary of Dementia Statistics, Investments and National Strategies for all 10 Countries

\begin{tabular}{|c|c|c|c|c|c|c|}
\hline Country & $\begin{array}{c}\text { Dementia } \\
\text { Strategy } \\
\text { Implementation } \\
\text { Year } \\
\end{array}$ & $\begin{array}{c}\text { Dementia Population } \\
\text { (Current) }\end{array}$ & $\begin{array}{c}\text { Total } \\
\text { Population } \\
\text { (Dementia \%) }\end{array}$ & $\begin{array}{l}\text { Future Dementia } \\
\text { Population } \\
\text { Estimates (Year) }\end{array}$ & $\begin{array}{l}\text { Investments } \\
\text { (Current) }\end{array}$ & $\begin{array}{c}\text { Future Investments } \\
\text { Estimates } \\
\text { (Year) }\end{array}$ \\
\hline USA & 2012 & 530,0000 & $\begin{array}{c}318,900000 \\
(1.65 \%)\end{array}$ & $\begin{array}{c}138,0000 \\
(2050)\end{array}$ & 216\$ billion & $\begin{array}{l}\text { 1.1\$ trillion } \\
(2050)\end{array}$ \\
\hline UK & 2009 & 850,000 & $\begin{array}{c}62,798,099 \\
(1.62 \%)\end{array}$ & $\begin{array}{c}100,0000 \\
(2025)\end{array}$ & $37 \$$ billion & $\begin{array}{l}\text { 47\$ billion } \\
(2050)\end{array}$ \\
\hline Canada & NA & 747,000 & $\begin{array}{c}351,60000 \\
(2.13 \%)\end{array}$ & $\begin{array}{c}149,4000 \\
(2031)\end{array}$ & $33 \$$ billion & $\begin{array}{c}\text { 293\$ billion } \\
(2040)\end{array}$ \\
\hline Sweden & 2010 & 173,135 & $\begin{array}{c}9,495,392 \\
(1.82 \%)\end{array}$ & $\begin{array}{c}250,000 \\
(2050)\end{array}$ & 7.2\$ billion & NA \\
\hline Italy & 2014 & 100,0000 & $\begin{array}{c}60,964,145 \\
(2.09 \%)\end{array}$ & NA & 12.3\$ billion & NA \\
\hline Germany & NA & $1,572,104$ & $\begin{array}{c}81,990,837 \\
(1.92 \%)\end{array}$ & $\begin{array}{c}2500000 \\
(2030)\end{array}$ & 2.6\$ billion & NA \\
\hline Netherlands & 2012 & 245,560 & $\begin{array}{c}16,714,228 \\
(1.47 \%) \\
\end{array}$ & NA & 3.35\$ billion & NA \\
\hline France & 2000 & $1,174,956$ & $\begin{array}{c}63,457,777 \\
(1.85 \%)\end{array}$ & NA & 7.85\$ billion & NA \\
\hline Australia & 2006 & 342,800 & $\begin{array}{c}231,30000 \\
(1.48 \%)\end{array}$ & $\begin{array}{c}100,0000 \\
(2050)\end{array}$ & 4.9\$ billion & $\begin{array}{l}\text { 83\$ billion } \\
(2060)\end{array}$ \\
\hline Spain & NA & 818,347 & $\begin{array}{c}46,771,596 \\
(1.75 \%)\end{array}$ & NA & 16.7\$ billion & NA \\
\hline
\end{tabular}

